Portland State University

PDXScholar

Winter 2013

\title{
A Community-Based Participatory Research Approach to Developing the Harvest for Healthy Kids Curriculum
}

\author{
Betty T. Izumi \\ Portland State University, izumibet@pdx.edu \\ Amanda M. Peden \\ Oregon Public Health Institute \\ Jennifer A. Hallman \\ Mt. Hood Community College \\ Dawn Barberis \\ Mt. Hood Community College \\ Brie Stott \\ Mt. Hood Community College

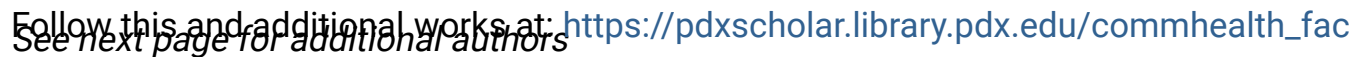 \\ Part of the Community Health Commons \\ Let us know how access to this document benefits you.
}

\section{Citation Details}

Izumi, B. T., Peden, A. M., Hallman, J. A., Barberis, D., Stott, B., Nimz, S., ... \& Capello, A. (2013). A community-based participatory research approach to developing the Harvest for Healthy Kids curriculum. Progress in community health partnerships: research, education, and action, 7(4), 379-384.

This Article is brought to you for free and open access. It has been accepted for inclusion in Community Health Faculty Publications and Presentations by an authorized administrator of PDXScholar. Please contact us if we can make this document more accessible: pdxscholar@pdx.edu. 


\section{Authors}

Betty T. Izumi, Amanda M. Peden, Jennifer A. Hallman, Dawn Barberis, Brie Stott, Sandy Nimz, William R. Ries, and Angela Capello 


\section{A Community-Based Participatory Research Approach to Developing the Harvest for Healthy Kids Curriculum}

Betty T. Izumi, PhD, MPH, RD ${ }^{1}$, Amanda M. Peden, $\mathrm{MPH}^{2}$, Jennifer A. Hallman ${ }^{3}$, Dawn Barberis, EdD ${ }^{3}$, Brie Stott, MS ${ }^{3}$, Sandy Nimz, BS, CFLE ${ }^{3}$, William R. Ries, $\mathrm{MS}^{3}$, and Angela Capello, BS

(1) Portland State University School of Community Health; (2) Oregon Public Health Institute; (3) Mt. Hood Community College Child Development and Family Support Program Head Start and Early Head Start

Submitted 20 July 2012, revised 14 November 2012, accepted 21 November 2012

\section{Abstract}

Background: A diet rich in fruits and vegetables is associated with reduced risk of diet-related chronic diseases. However, fewer than half of children in the United States consume the recommended amount.

Objectives: This article describes the community-based participatory research (CBPR) process used to develop the Harvest for Healthy Kids curriculum.

Methods: Harvest for Healthy Kids is a intervention research project designed to increase access to and intake of fruits and vegetables among preschoolers enrolled in Head Start. The curriculum is composed of eight kits, each focusing on a different fruit or vegetable.
Results: The Harvest for Healthy Kids curriculum was developed through an iterative process in which Head Start teachers were highly involved. The final product reflects the teachers' experiences using the curriculum and their suggestions for improving.

Conclusions: The CBPR process used to develop the Harvest for Healthy Kids curriculum led to a product that is grounded in theory and practice.

Keywords

Community-based participatory research, nutrition, childhood obesity, intervention
A diet rich in fruits and vegetables is associated with reduced risk of obesity and other diet-related chronic diseases, ${ }^{1}$ yet fewer than half of children in the United States meet Dietary Recommendations ${ }^{2}$ for fruits and vegetables. ${ }^{3,4}$ Although a number of fruit and vegetable interventions targeting school-age children have been developed, they are in many ways too late; by kindergarten entry, children have already consumed thousands of meals and snacks, and have learned what foods they like and do not like. ${ }^{5}$ With a record number of young children in some form of nonparental care each week, ${ }^{6}$ childcare settings (e.g., Head Start, day care, preschool) have emerged as important environments in which to promote healthy eating habits among young children. ${ }^{7}$
Increasingly, researchers are using CBPR to develop health promotion interventions. Because of its emphasis on co-learning, ${ }^{8}$ CBPR may be particularly useful for developing nutrition interventions in childcare settings ${ }^{9}$ - an area of research still in its infancy. ${ }^{7}$ Researchers, for example, can contribute knowledge of theories used to develop and evaluate nutrition education programs, and childcare providers can bring essential insights into the developmental appropriateness of the intervention as well as intervention feasibility given factors such as resource and space constraints. When applied to the development of health promotion curricula, CBPR ensures that the end user (i.e., interventionist) helps to shape the curriculum, leading to an intervention with greater local relevance $e^{10-16}$ and implementation integrity. ${ }^{13,17,18}$ In this 
article, we describe the CBPR process used to develop the classroom education component of Harvest for Healthy Kids, a nutrition intervention research project designed to increase access to and intake of fruits and vegetables among 3- to 5-year-old children enrolled at Mt. Hood Community College Head Start (Portland, Oregon).

\section{METHODS}

\section{Partnership}

Harvest for Healthy Kids represents the work of a community-academic partnership between the Mt. Hood Community College Head Start program (herein called Head Start) and the School of Community Health at Portland State University. Head Start currently serves approximately 1,000 preschool-age children across 12 centers in Multnomah County, Oregon. Enrolled children come from families with low incomes (i.e., at or below the federal poverty level of $\$ 23,050$ for a family of four ${ }^{19}$ ) and diverse racial backgrounds (e.g., American Indian, Alaska Native, Pacific Islander, Black or African American, Hispanic). Individuals from both partnership institutions serve as project directors and coordinators; Head Start oversees program implementation and Portland State oversees evaluation activities. This structure promotes shared leadership, decisionmaking power, and responsibility for partnership goals. Since 2010, the partnership has met at least monthly to design the research, collaborate on grant writing, and carry out project activities. The frequent contact has allowed project partners to continuously assess the project and make necessary improvements. In addition to working meetings, project partners gather regularly to celebrate milestones achieved. Harvest for Healthy Kids is guided by a steering committee that is made up of individuals with expertise in child nutrition, agriculture, and/or childcare settings. The individuals represent the following organizations, institutions, and businesses: Head Start, Portland State University, Oregon Health \& Sciences University, Dancing Roots Farm, Food Services of America (primary foodservice distributor for Head Start), Child Care Resource and Referral Network of Multnomah County, and Ecotrust (a local nonprofit organization and regional lead agency of the National Farm to School Network ${ }^{20}$ ). Representatives from Head Start include teachers, administrators, and a parent who is a member of the Policy Council, a group of parent representatives and community members that review, advise, and approve local Head Start policies and procedures. The steering committee meets quarterly to discuss project challenges, provide feedback on project components (e.g., recipes, curriculum, parent outreach), and brainstorm mechanisms for future funding. In 2011, we received our first grant from Kaiser Permanente Northwest. The funding supports the first three phases of the Harvest for Healthy Kids intervention research project: (1) development, (2) pilot testing, and (3) dissemination. All Harvest for Healthy Kids research activities have been approved approval by the Portland State University Institutional Review Board for Protection of Human Subjects.

\section{Conceptual Framework}

Harvest for Healthy Kids is modeled after farm-to-school efforts in Kindergarten through 12th grade schools, which simultaneously promote healthy eating habits through repeated exposure to a variety of fruits and vegetables and contribute to a vibrant and resilient local food system. ${ }^{21-24}$ Farm-to-school has been identified by the U.S. Centers for Disease Control and Prevention as an effective and innovative way to increase fruit and vegetable intake among school-age children ${ }^{25}$ and policy makers at both the national and local levels have passed legislation (e.g., Farm to School Grant Program, Healthy Hunger-Free Kids Act; [Oregon] Farm to School and School Garden Bill) encouraging schools to buy locally grown foods for their cafeterias. ${ }^{26,27}$ Of the few relevant studies, nine of eleven have shown an increase in student intake of fruits and vegetables after farm-fresh produce was incorporated into the cafeteria or introduced through in-class education..$^{28}$ In recent years, the farm-to-school concept has been introduced to preschool aged children in childcare in an effort to promote fruit and vegetable intake during a critical period for the development of lifelong food preferences.

The conceptual framework for Harvest for Healthy Kids is the ecological model, ${ }^{29}$ which emphasizes multiple levels of influence on behavior (e.g., interpersonal, institutional). Social cognitive theor $\mathrm{y}^{30}$ constructs (e.g., observational learning, selfefficacy, positive reinforcement, and environmental changes to support fruit and vegetable intake) provide theoretical grounding for the intervention. The classroom education curriculum is composed of eight kits, each focusing on a different fruit or vegetable (or family of vegetables such as winter root 
vegetables), with four key elements: Activity plans, picture cards, educator newsletters, and family newsletters.

\section{RESULTS}

The Harvest for Healthy Kids curriculum was developed through an iterative process in which Head Start teachers were highly involved. During the 2010 and 2011 academic year, a graduate research assistant enrolled in the Oregon Master of Public Health program served as the academic project coordinator and led the partnership through the curriculum development process. The process, described below, was guided by the three research questions: (1) What is already known that can be applied to the Harvest for Healthy Kids curriculum? (2) Is the curriculum usable by Head Start teachers? (3) How can the curriculum be improved to serve educators in childcare settings?

\section{Review of the Literature}

The academic project coordinator consulted with educators engaged in farm-to-childcare work and conducted a literature search to identify existing theory- and evidencebased curricula designed to connect preschool-age children with locally grown fruits and vegetables that could be added to Head Start meals. No single curriculum met these criteria, although several included promising components that could be adapted for Harvest for Healthy Kids: Color Me Healthy, a theory- and evidence-based nutrition and physical activity program for children ages 4 and 5 years ${ }^{31}$; Grow It, Try It, Like It, a garden-themed nutrition education program for preschool-age children in childcare ${ }^{32}$; and Harvest of the Month, a California farm-to-school program for children in preschool ${ }^{33}$ and grades Kindergarten through $12 .{ }^{34}$ The educators also shared a number of relevant resources including read-aloud books and hands-on activities that could be adapted for use with preschool-age children in Oregon. The curricula and resources identified were discussed at a partnership meeting and a decision was made to adapt existing and develop new materials given that no single curriculum was designed to educate preschool-age children in childcare settings about fruits and vegetables that are both grown in Oregon and seasonally available during the academic year.

\section{Draft Curriculum}

The academic project coordinator drafted the first kit of the curriculum (focused on "beets"), which included an activity plan, family newsletter, and picture cards (cards with colorful pictures and simple text that help young children to learn about fruits and vegetables, including how they grow). The community partners contributed to the module by aligning it with Head Start policies and practices and by ensuring that the curriculum elements were developmentally appropriate for preschool-age children and culturally relevant for the diverse backgrounds of the families served by Head Start.

\section{Deliver Curriculum}

One center with three classrooms was chosen to participate in the curriculum development phase of the project because of the center's capacity to easily integrate featured fruits and vegetables into its foodservice program and test Harvest for Healthy Kids recipes. The three teachers at the center were invited to provide feedback on the modules, beginning with the "beet" kit. The teachers were also encouraged to experiment with their own ideas for integrating the featured foods into their classrooms. At the beginning of each month, the community project coordinator provided teachers with materials and supplies (e.g., ingredients and equipment for cooking activities, read-aloud books) to implement the curriculum. At the end of each week, the academic project coordinator conducted check-in phone calls (short, semistructured interviews) with each of the teachers to assess their use of the curriculum materials that week. Interview questions included: What, if any, curriculum materials did you use this week? What are your suggestions for improving the curriculum materials? What questions or concerns do you have about Harvest for Healthy Kids? Phone calls were recorded and notes were taken on contact summary forms. ${ }^{35}$ Over the 8-month period, the academic project coordinator conducted 66 phone calls. On average, the phone calls lasted approximately 20 minutes. At the end of each month, an inperson, 1.5-hour group meeting with teachers and project staff was held at the center to debrief the teachers' experiences with the module. Because the center meetings were held in teachers' classrooms, the meetings also offered a chance for the teachers to show project staff examples of how they integrated the featured foods into classroom activities. For example, one teacher established a classroom "garden" on an area of her bulletin board using children's artistic renderings of featured 
fruits and vegetables. The group meetings also provided an opportunity for the teachers and project staff to develop and review drafts of the picture cards. Project staff took detailed notes during the meetings and debriefed immediately after about main themes that emerged. Direct observation provided a third method for gathering information about how teachers integrated Harvest for Healthy Kids into their classrooms. Over the 8-month period, the academic project director and coordinator conducted a total of three full-day (5-hour) observations. The purpose of the observations was to document, using photographs and stories, how Harvest for Healthy Kids was being implemented in the classroom. The photographs and stories were used to enrich the activity plan with concrete examples of curriculum implementation. Given that monthly research results were needed soon after each data collection point in order to incorporate findings into the following kits, applied thematic analyses targeted toward discovering themes with practical curriculum applications.

\section{Revise Curriculum}

The academic project coordinator revised the kits based on four themes. First, the teachers requested a more "userfriendly" format for the activity plans. The format of the original activity plan, organized by specific lessons and activities to implement each week (e.g., week 1, Read-Aloud Book), made it difficult for teachers to easily integrate the curriculum into their daily schedules. Therefore, the academic project coordinator modified the activity plans with lessons and activities organized into categories that reflected the rhythm and realities of a typical preschool day: Circle time, meal time, and activity time. To further integrate the curriculum into the Head Start program, the activity plans were also aligned with the Head Start Child Development and Early Learning Framework. ${ }^{36}$ Second, the teachers suggested adding activities that could be used to transition children from one activity to the next and that required few resources (time, money, supplies) and minimal preparation. The teachers shared ideas such as "paper bag guessing game" and "clap-it-out" activities (e.g., ru-ta-ba-ga), which they used during transitions and when the classroom environment made it too difficult to implement, for example, a cooking activity; these ideas became the content for the fourth category of the activity plans: Fast and fun. Third, the teachers did not always feel confident they had the background information necessary to introduce the featured foods to the children. To address this concern, the academic project coordinator worked closely with a farmer who was also a member of the Harvest for Healthy Kids steering committee to develop monthly educator newsletters, called "Teacher Bites," to familiarize the teachers with the featured fruits and vegetables and to develop teachers' confidence in introducing the foods to the children. Fourth, the teachers recommended that the curriculum promote depth versus breadth of experiences with featured fruits and vegetables. For example, the month of January originally focused on head cabbage, collards, and kale-all of which are vegetables in the cabbage family. During the first check-in phone call that month, the teachers expressed concern that integrating head and leafy cabbages into classroom activities during a single month was too overwhelming for the children. The teachers suggested focusing exclusively on head cabbage. That month, they improvised and developed their own lessons and activities; these became the primary content for the month focused on head cabbage.

\section{Finalize Curriculum}

To finalize the kits, community and academic partners edited the text of the activity plans, family newsletter, picture cards, and educator newsletters; translated the family newsletters into Spanish and Russian; and worked with a graphic designer who prepared the kits for pilot testing.

\section{NEXT STEPS}

The teachers who participated in the curriculum development phase of the project worked with project staff to develop and conduct the Harvest for Healthy Kids pilot study teacher training, which took place immediately before 2012 through 2013 academic year. Additionally, they currently provide critical peer-to-peer support for the teachers participating in the pilot phase of the project. As part of the pilot study, outcome and process evaluations are being conducted. To evaluate the main outcome of interest, the impact of Harvest for Healthy Kids on children's willingness to try and liking of featured fruits and vegetables, we will use taste tests and ageappropriate surveys. The process evaluation will examine how Harvest for Healthy Kids is implemented during the pilottesting phase using weekly check-in phone calls, in-person group meetings, and direct observation. 


\section{LESSONS LEARNED}

The teachers who participated in the CBPR process described herein played an instrumental and invaluable role in the development of the Harvest for Healthy Kids curriculum and the intervention as a whole. The Partners identified the following lessons learned for consideration by individuals and community-academic partnerships interested in using a CBPR approach to develop intervention curricula.

1. Build in time and resources for multiple iterations of intervention curricula. Significant time and resources are needed to use a CBPR approach to develop intervention curricula. During the "revise curriculum" phase, numerous drafts were circulated among the partners, including the teachers. During this process, the partnership benefited from a grant from Kaiser Permanente Northwest, which provided resources to hire an academic project coordinator with an interest in CBPR and child nutrition who could lead the partnership through the curriculum development process.

2. Engage a diversity of interventionists in developing intervention curricula. Engaging a diversity of interventionists in the curriculum development phase of Harvest for Healthy Kids strengthened the curriculum by including the perspectives of teachers with diverse teaching experiences, varying levels of interest in Harvest for Healthy Kids, and different classroom environments.

3. Use multiple evaluation methods to assess curriculum usage. Using multiple methods for assessing curriculum usability is time and resource intensive. However, the weekly check-in phone calls, monthly in-person group meetings, and direct observation provided opportunities to capture teachers' experiences as they occurred and document the teachers' reflections about and experiences with the program.

\section{CONCLUSION}

Increasingly, childcare providers and parents share responsibility for children, making childcare settings important environments in which to promote healthy eating habits. This article draws on the experience of one community-academic partnership in developing the Harvest for Healthy Kids classroom education curriculum, a set of eight kits designed to introduce preschool-age children to locally grown fruits and vegetables. Using a CBPR process to develop the curriculum provided an opening to engage community partners in the development phase of the project, thereby enhancing the likelihood that the curriculum would be acceptable to Head Start teachers, children, and families. The research questions and curriculum development steps described here provide a framework for participatory curriculum development. The lessons learned underscore the importance of allocating sufficient resources for gathering feedback for incorporation into the final product. Childcare settings provide a relatively untapped opportunity for developing interventions to improve children's eating habits. Engaging community partners in the development phase of intervention research can enhance intervention effectiveness and intervention sustainability.

\section{ACKNOWLEDGMENTS}

The authors thank the Harvest for Healthy Kids steering committee for their contributions to the work presented herein, including representatives from MHCC Head Start, Portland State University, Oregon Health \& Sciences University, Dancing Roots Farm, Food Services of America, Child Care Resource and Referral Network of Multnomah County, and Ecotrust; Kaiser Permanente Northwest for its support; Natalie Thompson, Molly Nicholie, Helene Hanson, Rosa Romero, Karrie Kalich, and Carolyn Dunn, for sharing their curriculum development experiences; and the journal editors and two anonymous peer reviewers for their insights and detailed suggestions.

\section{REFERENCES}

1. World Cancer Research Fund, American Institute for Cancer Research (AICR). Food, nutrition, physical activity, and the prevention of cancer: A global perspective. Washington (DC): AICR; 2007.

2. U.S. Department of Agriculture, U.S. Department of Health and Human Services. Dietary Guidelines for Americans 2010 [cited 2012 Sep 19]. Available from: http://www.health .gov/dietaryguidelines/dga2010/DietaryGuidelines2010.pdf

3. Rasmussen M, Krolner R, Klepp KI, Lytle L, Brug J, Bere E, et al. Determinants of fruit and vegetable consumption among children and adolescents: A review of the literature. Part I: Quantitative studies. Int J Behav Nutr Phys Act. 2006;3:22.

4. Guenther PM, Dodd KW, Reedy J, Krebs-Smith SM. Most Americans eat much less than recommended amounts of fruits and vegetables. J Am Diet Assoc. 2006;106(9):1371-9. 
5. Birch LL. Development of food preferences. Annu Rev Nutr. 1999;19:41-62.

6. National Association of Child Care Resource \& Referral Agencies. Who's minding the kids? Child care arrangements [cited 2012 Apr 9]. Available from: http://www.naccrra.org /sites/default/files/default_site_pages/2011/povertyonepager final.pdf

7. Story M, Kaphingst KM, French S. The role of child care settings in obesity prevention. Future Child. 2006;16(1):143-68.

8. Israel BA, Eng E, Schulz AJ, Parker EA, editors. Methods in community-based participatory research for health. San Francisco: John Wiley \& Sons; 2005.

9. Spark A, Pfau J, Nicklas TA, Williams CL. Reducing fat in preschool meals: Description of the foodservice intervention component of Healthy Start. J Nutr Educ. 1998;30(3):170-7.

10. Davis SM, Going SB, Helitzer DL, Teufel NI, Snyder P, Gittelsohn J, et al. Pathways: A culturally appropriate obesityprevention program for American Indian schoolchildren. Am J Clin Nutr. 1999;69S:796S-802S.

11. Diwan S, Wertheimer MR. Aging services or services to the aging? Focus of a university-community curriculum development partnership to increase awareness of aging issues in social work practice. J Gerentol Soc Work. 2007;50:187-204.

12. Gregg J, Solotaroff R, Amann T, Michael Y, Bowen J. Health and disease in context: A community-based social medicine curriculum. Acad Med. 2008;83(1):14-9.

13. Bermudez Parsai M, Gonzalez Castro F, Marsiglia FF, Harthun ML, Valdez H. Using community-based participatory research to create a culturally grounded intervention for parents and youth to prevent risky behaviors. Prev Sci. 2011;12:34-47.

14. LaRowe TL, Wubben DP, Cronin KA, Vannatter SM, Adams AK. Development of a culturally appropriate, home-based nutrition and physical activity curriculum for Wisconsin American Indian Families. Prev Chronic Dis. 2007;4(4):1-8.

15. Leff SS, Thomas DE, Vaughn NA, Thomas NA, MacEvoy JP, Freedman MA, et al. Using community-based participatory research to develop the PARTNERS Youth Violence Prevention Program. Prog Commun Health Partnersh. 2010;4(3):207-16.

16. Masters H, Forrest S, Harley A, Hunter M, Brown N, Risk I. Involving mental health service users and carers in curriculum development: Moving beyond "classroom" involvement J Psychiatr Mental Health Nurs. 2002;9:309-16.

17. Natasi BK, Varjas K, Schensul SL, Silva KT, Schensul JJ, Ratnayake P. The participatory intervention model: A framework for conceptualizing and promoting intervention acceptability. Sch Psychol Q. 2000;15(2):207-32.

18. Power TJ, Blom-Hoffman J, Clarke AT, Riley-Tillman TC, Kelleher C, Manz PH. Reconceptualizing intervention integrity: A partnership-based framework for linking research with practice. Psychology in Schools. 2005;42(5):495-507.

19. U.S. Department of Health and Human Services. 2012 HHS poverty guidelines [cited $2012 \mathrm{Jul} 20$ ]. Available from: http:// aspe.hhs.gov/poverty/12poverty.shtml/

20. National Farm to School Network. Farm to school [cited 2011 Apr 5]. Available from: http://www.farmtoschool.org
21. Izumi BT, Wright DW, Hamm MW. Farm to school programs: exploring the role of regionally-based food distributors in alternative agrifood networks. Agric Human Values. 2009; July 26.

22. Izumi BT, Alaimo K, Hamm MW. Farm-to-school programs: Perspectives of school food service professionals. J Nutr Educ Behav. 2010;42(2):83-91.

23. Izumi BT, Wright DW, Hamm MW. Market diversification and social benefits: Motivations of farmers participating in farm to school programs. J Rural Stud. 2010; 26:374-382.

24. Izumi BT, Rostant OS, Moss MJ, Hamm MW. Results from the 2004 Michigan Farm-to-School Survey. J School Health. 2006;76(5):169-74.

25. U.S. Centers for Disease Control and Prevention. CDC Congressional testimony: Benefits of farm-to-school projects, healthy eating and physical activity for school children [cited 2010 Jul 19]. Available from: http://www.cdc.gov/washington /testimony/2009/t20090515.htm

26. U.S. Department of Agriculture. Healthy Hunger-Free Kids Act of 2010 [cited 2012 Sep 20]. Available from: http://www .fns.usda.gov/cnd/governance/legislation/cnr_2010.htm

27. Upstream Public Health. Health Impact Assessment HB 2800: Oregon Farm to School and School Garden Policy. Available from http://www.upstreampublichealth.org/resources/healthimpact-assessment-hb-2800-farm-school

28. Joshi A, Azuma AM, Feenstra G. Do farm-to-school programs make a difference? Findings and future research needs. J Hunger Environ Nutr. 2008;3(2-3):229-46.

29. Bronfenbrenner U. Ecological models of human development. In: Gauvain M, Cole M, editors. Readings on the development of children. New York: Freeman; 1993:37-43.

30. Bandura A. Social foundations of thought and action. Englewood Cliffs (NJ): Prentice-Hall; 1986.

31. Witt KE, Dunn C. Increasing fruit and vegetable consumption among preschoolers: Evaluation of Color Me Healthy. J Nutr Educ Behav. 2012;44:107-13.

32. U.S. Department of Agriculture. Grow It, Try It, Like It! Preschool Fun With Fruits and Vegetables [cited 2012 Jun 27]. Available from: http://www.fns.usda.gov/tn/Resources/growit _book1.pdf

33. California Department of Public Health. Harvest of the Month Preschool Activity Packet [cited 2012 Nov 12]. Available from: http://publichealth.lacounty.gov/nut/LACOLLAB_Files /documents/HOTM/Rotation_2010-2011/04\%20DecemberPears/Preschool\%20Activity\%20Packet_Pears.pdf

34. California Department of Public Health Cancer Prevention and Nutrition Section. Harvest of the month: Growing healthy students [cited 2011 Mar 14]. Available from: http://www. harvestofthemonth.com/

35. Miles MB, Huberman AM. Qualitative data analysis. Thousand Oaks (CA): Sage; 1994.

36. Office of Health Start, Administration for Children and Families, U.S. Department of Health and Human Services. Available from http://eclkc.ohs.acf.hhs.gov/hslc/tta-system/teaching /eecd/Assessment/Child\%20Outcomes/HS_Revised_Child_ Outcomes_Framework(rev-Sept2011).pdf 